\title{
miscellany
}

\section{Divisional Research Prize}

The Eastern Division Research Prize was created in 2002 to encourage and reward research. It is open to all doctors of nonconsultant grade working within the Eastern Division. The closing date for submissions is March 2004. The entries will be judged by three examiners to include the Chairman, plus one Executive Member and one Co-opted Member. The prize is $\mathrm{f500}$ plus Certificate, and will be awarded at the AGM in May 2004. There will be the opportunity for the researcher to present their work at a later academic programme.

For more information on the prize, please contact the Chairman, Dr Christopher Mayer. Submissions should be sent to: christopher.mayer@lhp.nhs.uk

\section{forthcoming events}

\section{A Disaster Has Happened 'What} can we expect?' is the title of the second care line seminar organised by Sunderland Counselling Services. The seminar will take place in Sunderland on 17-18 September 2003. Experts in their field, the speakers will aim to provide a wide-ranging and comprehensive view of the differing perspectives that are associated with the aftermath of a critical incident and the ways in which we deal with disasters and stress-related issues. For further information, please contact Sunderland Counselling Services (tel: 0191514 7007; e-mail: info@ slandcouns.co.uk).

Professor R N Mohan, Consultant in Old Age Psychiatry, Birmingham \& Solihull Mental Health NHS Trust is the organiser of the following courses: the

Birmingham MRCPsych Part II

Revision Course will take place on 3-5 September 2003; Mental Health Law - Dispelling Myths \& Recent Developments will be held on 22-23 October 2003 and again on 12-13 November 2003. A leading mental health solicitor, Peter Edwards, will be the course speaker/facilitator and will focus on key issues related to the Mental Health Act 1983 and mental health law. Finally, the Management Course for Specialist Registrars in Psychiatry will take place on 27-28 November 2003. This course will cover NHS structures and functions, terms and conditions of service and negotiating a consultant job. For further information on any of these courses please contact Mrs Julie McKenzie on 0121685 6570. All courses will be held at the Birmingham Medical Institute.

The Afiya Trust would like to announce the following conference, which will be held on 15-16 September 2003 in Manchester: Black \& Minority Ethnic mental health - a national 2-day conference to radically alter the mainstream perception of, and response to, Black and minority ethnic (BME) mental health issues. This conference will address the major shortfalls in much of current mental health practice by demonstrating existing good practice for working with BME mental health service users, in alternative treatment approaches and therapies, highlighting the wealth of lay and professional experience that exists, but is underutilised, in BME communities; and by reviewing major reports and policy documents, and examining the practical development of some of these recommendations. The intention will be to develop a national BME mental health network which will promote culturally competent policy, good practice and training. A key objective is development of an accredited training scheme to enable lay BME people to participate in treatment. Speakers will include senior mental health professionals from both the statutory and voluntary sector and also BME community mental health agencies. For further information, please call 0115916 3104 or e-mail: ccclimited@aol.com. Alternatively, visit The Afiya Trust website: http://www. afiya-trust.org.

The Andrew Sims Centre would like to announce: Women in Mental Health Services, Women As Users, Women As Providers a one-day conference that will take place on 3 October 2003 in Leeds. This conference will address and discuss current issues and is aimed at a multidisciplinary audience including psychiatrists, psychotherapists, general practitioners, nurses, professions allied to medicine and colleagues from the voluntary sector. For further information please contact the Course Administrator, The Andrew Sims Centre, Leeds Mental health Trust (tel: 01132953958 or 07985 863619; e-mail: AndrewSimsCentre@cwcom.net; website: http://www.leedsmentalhealth.nhs.uk/ andrewsims.

Meeting the Challenge - New Roles, Relationships and Responsibilities in
Primary Care Mental Health is the title of a conference taking place on 3 October 2003 in Manchester. The conference is sponsored by the National Primary Care Research and Development Centre, the Primary Care Mental Health Research Group, the University of Manchester, and the Institute of Health Sciences. The event is aimed at primary care professionals (clinicians and managers) concerned with planning, delivering and managing mental health care in primary care settings, primary care mental health research workers and educators. For further information please contact Helena Wilton, Communications Assistant, National Primary Care Research and Development Centre (tel: 0161275 7610; 0161275 0611; e-mail: hwilton@fsl.cpcr.man.ac.uk).

The Transcultural Special Interest Group Annual Conference, Effective mental health provision for black and minority ethnic groups; Service model and interpretation services, will be held on 7 October 2003 at the Warren Suite, Royal College of Psychiatrists, 17 Belgrave Square, London SW1 8PG. For further details please contact Mrs G Medhurst (except Fridays); tel: 0207882 7555; fax: 0207882 7551; e-mail: g.medhurst@qmul.ac.uk.

The 11th Scientific Meeting of The Pacific Rim College of Psychiatrists will be held on 27-30 October 2003 in Hong Kong. Interested parties should contact the Meeting Secretariat, c/o Meeting Planners International (HK) Ltd, 22/F, Pico Tower, 66 Gloucester Road, Wanchai, Hong Kong SAR. Tel: +852 2509 3430; fax: +852 2667 6927; e-mail: PRCP@mphk.com.

\section{Corrigendum}

Reading Lights (book review) Psychiatric Bulletin, 27, 199: the name of the author of this review should read: Ann Gath. 